\title{
What we see, why we worry, why we hope: Vietnam going forward
}

\author{
Nancy K. Napier, Vuong Quan Hoang \\ Boise State University CCI Press
}

2013

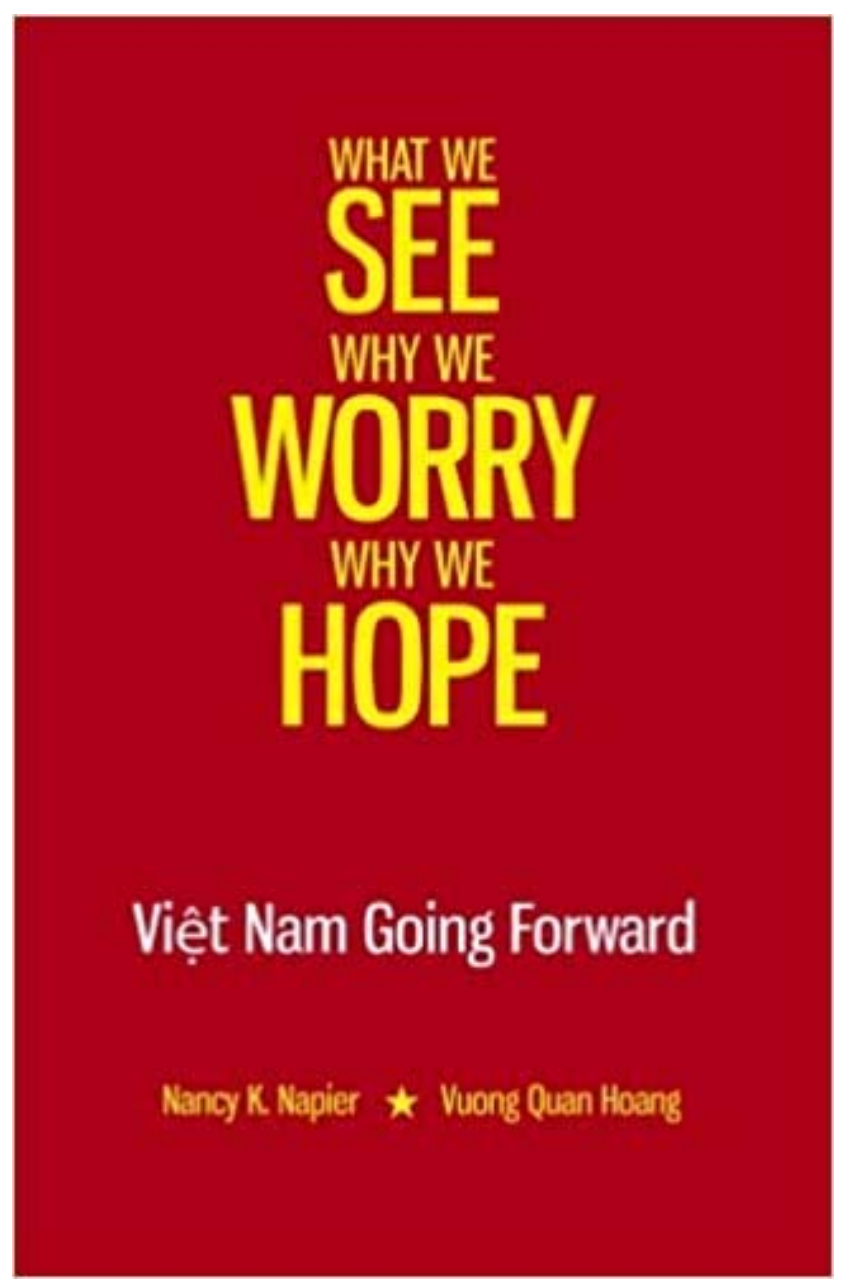



The time is ripe to create visibility into the Hidden Champions in Vietnam. This book is inspiring for entrepreneurs as well as those who work hard to put 91 million Vietnamese on the global agenda. Reading this book gives a better understanding why there is no future without understanding the diversity and wealth of Asean thinking.

Roland Schatz

Founder of Media Tenor, Zurich, Switzerland Co-author, The Global President: International Media and the US Government

Every story in the book is so beautifully written. Once I started reading it, I could not put it down until the last page. The authors used true stories of their personal life experience and that of others, from their early childhood days and how those experiences shaped their lives. Most of those real personalities are successful today.

By cleverly weaving these simple story lines, the authors raise some very provocative questions. Readers will find the stories and the questions irresistibly attractive and inspiring. But most importantly, behind each story, readers will get a vivid impression of the actor's inner thought, his emotion, his vision, his laughter, and sometimes his tears. Their stories mirror the aspirations and hope of the ordinary Vietnamese that you may come face to face with on the streets in the country.

With these stories, the writers see hope. They seek to share their views and perhaps offer an answer about how to navigate the critical pathways that can lead the nation to great prosperity.

A fascinating book.

Loke Kiang Wong

Retired Captain Singapore Navy Singapore Navy and Contributor to Vietnamica.net 
What we see, why we worry, why we hope provides valuable insight into the Vietnamese mindset. Useful for a student, traveler or businessperson, the anecdotes provide an insider's view into Vietnamese culture and its impact on the country's role in a dynamic region. Like Napier and Hoang, Stratfor holds a lot of hope for Vietnam as it transitions in a "post-China" era. Revealing anecdotes, woven throughout the authors' hopes and worries, offer a critical bridge for understanding a culture shaped by unique geopolitical circumstances, highlighting both the challenges and opportunities for Vietnam's future. In a chaotic world, Napier and Hoang are able to explore the essence of Vietnam in simple but compelling snapshots, providing critical insights for Vietnam's future.

George Friedman Chairman, Stratfor Author of The Next Decade and The Next 100 Years

So rich in real life stories that the book makes you "live Vietnam." The book elegantly weaves the past with the present, daily life with reflections, and the local with the global through the sharp observations by the authors.

Olav Jull Sørensen

Professor

Aalborg University, Denmark

Medal of Honor Recipient

Vietnam's Ministry of Education and Training 
A cogent and compelling look at contemporary Vietnam with all its complexities and contradictions. Vuong Quan Hoang and Nancy Napier have given us a well-written and accessible guide to understanding the changes that Vietnam has gone through in the last decade. This book will be of great use to anyone wanting to understand Vietnam today.

Anya Schiffrin Stiglitz Columbia University's School of International and Public Affairs

(Co)Author of From Cairo to Wall Street: Voices from the Global Spring and Bad Nens: How America's Business Press Missed the Story of the Century

We - Vietnamese entrepreneurs and businesspeople - who have the wish of making Vietnam a better place to work and live have both worries and hopes for our home country. The authors have done a nice job of presenting a new Vietnam, a multi-colored society and an emerging market economy, with simple and fun-to-read style. The book delivers many important messages to western readers; and we highly appreciate the great efforts by the authors trying to bring Vietnam to the world, and the world to Vietnam.

Vu Quang Hoi

Chairman

The Bitexco Group 


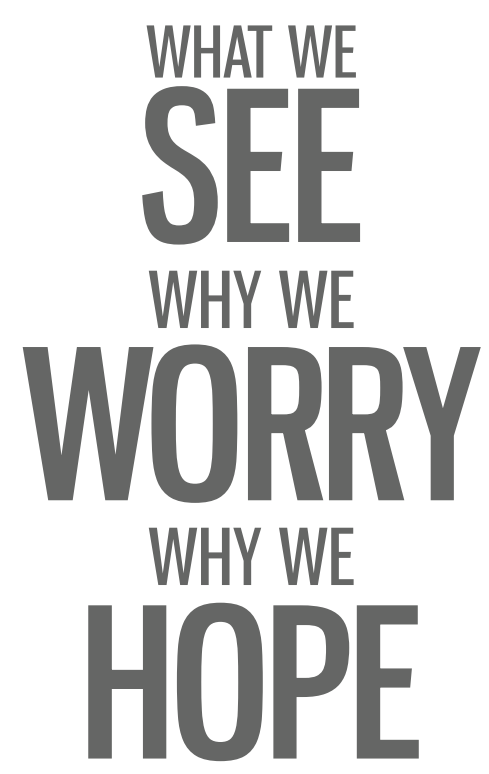

Việt Nam Going Forward 


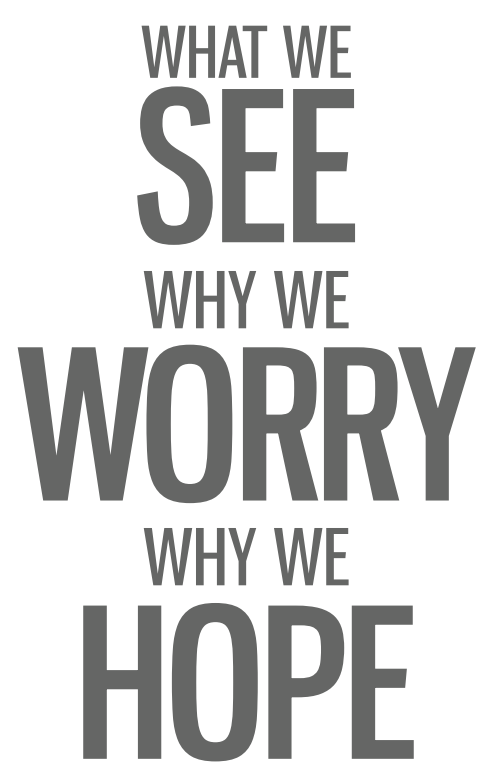

Việt Nam Going Forward

Nancy K. Napier $\star$ Vuong Quan Hoang

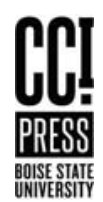


Copyright (C 2013 by Nancy K. Napier and Vuong Quan Hoang

All Rights Reserved

Printed in the United States of America

No part of this publication may be reproduced, stored in or introduced into a retrieval system, or transmitted, in any form, or by any means

(electronic, mechanical, photocopying, recording, or otherwise), without the prior permission of the publisher. Request for permission should be directed to ccipress@boisestate.edu, Permissions in subject line, or mailed to Permissions, CCI Press, Centre for Creativity and Innovation, Boise State University, 1910 University Drive, Boise, Idaho 83725-1635.

\section{PUBLISHED BY CCI PRESS}

Boise State University

Managing Editor: Stephanie Chism
Production Manager: Joanna Lui

ISBN 13: 978-0-9855305-8-7

CCI Press - http://cobe.boisestate.edu/cci/cci-press/ http://cobe.boisestate.edu/cci/vietnamgoingforward All trademarks are the property of their respective companies. 


\section{TABLE OF CONTENTS}

Foreword XIII

Introduction 1

Why this book now?

Why us? 10

Part I: WHAT WE SEE

The legacy of traditional Vietnamese cultural values $\quad 18$

The duck and the egg 24

A precious gift 27

Traditional social values at work 31

The closed world of trust 34

Changes in the making? 38

When the wrong answer is the right answer 41

Money as king? 43

Learning the hard way that market economics has risks 48

The wisdom of housewives $\quad 49$

Upside down market economics 51

The new world of choice 54

Part II: WHY WE WORRY

Cracks in traditional values? 62

Time, Vietnamese style 64

Short-term thinking, small dreams? 66

Who has the answers? 68 
Gain is the opposite of risk $\quad 71$

Am I as ready as I think I am? $\quad 74$

What's in it for me? 77

From fried eggs to a business degree $\quad 78$

China: The northern giant $\quad 80$

Will Vietnamese trust themselves? 81

Part III: WHY WE HOPE

Resourcefulness $\quad 88$

Resilience and the Four F's 91

Reinvention 95

The bridge generation 108

What do Vietnamese think about Americans? 116

Responsible creativity 117

Vietnam Factsheet 2012

Acknowledgements 123

About the Authors $\quad 125$ 


\section{Foreword}

This is an excellent book from which to learn about the real changes happening in Vietnam, a country that is experiencing one of the most rapid economic growth periods in the world, and is undergoing a radical change in its society. The book includes a very vivid description of the "bridge generation" - the generation, a group that bridges the old communist era and the free market era of the current transition economy. This generation knows both the Vietnam War (or as the Vietnamese say, The American War) and the Doi Moi economic reforms, which began in the 1980s. Of the people interviewed for the book, some were successful in business, while others failed repeatedly and eventually succeeded. Readers will be impressed by the stories about these and others described in the book.

Napier and Hoang describe the socio-economic challenges which Vietnam is facing. Readers' understanding of the book would be enhanced by some knowledge of the history behind the country's economic reforms. For example, the reform of state owned enterprises (SOEs) has been pursued with a philosophy "gradualism" and Vietnam initiated its agricultural reforms in the 1980s, and its opening to foreign trade in the 1990s.

I anticipate that this book will not only contribute to the general public's understanding of Vietnam, but also stimulate academic interests. If we look at countries and regions in East Asia, those with a Confucian background have achieved solid economic development. Japan, Korea, and China all have strong Confucian backgrounds, and their entrepreneurs are often influenced by Confucian ideas. Vietnam has a cultural and historical background, which is similar to those 
East Asian countries and regions. When Vietnam develops further, its corporations and entrepreneurs will need a corporate identity that will support their stability. I wonder where the Vietnamese corporations will find solutions. Whether they can successfully build their corporations based on a mix of Vietnamese socio-cultural values and emerging Western ideas of development remains a difficult question.

Junichi Mori

Vice President for International Relations

Director \& Professor

The International Center, Kyoto University 


\section{About the Authors}

Nancy K. Napier is Professor of Strategy and Executive Director of the Centre for Creativity and Innovation at Boise State University (USA) and Adjunct Professor of International Business at Aalborg University (Denmark). She holds the Medal of Honor from Vietnam's Ministry of Education and Training, in part for her work managing Boise State's involvement in a nine-year $\$ 8.5$ million capacity building project at the National Economics University (Hanoi, Vietnam).

Vuong Quan Hoang received an MBA from Boise State University, a PhD from the University of Brussels, is cofounder of the Hanoi-based DHVP Research \& Consultancy, and also serves as researcher at Centre Emile Bernheim, Université Libre de Bruxelles (Belgium). He was awarded Vietnam's National Book Prize 2007 and National Journalism Prize 2010. 